\title{
Associação Entre Discinesia Escapular e Dor no Ombro de Praticantes de Natação
}

\author{
Association Between Scapular Dyskinesia and Shoulder Pain \\ In Swimmers
}

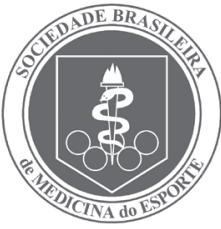

Artigo Original

\author{
Elis Passos Santana \\ Bruno César Ferreirar ${ }^{2}$ \\ Gabriel Ribeiro 3 \\ 1. Universidade Católica do Salvador \\ Salvador, Bahia. \\ 2. Faculdades Integradas da Bahia, \\ Salvador, Bahia. \\ 3. Centro Universitário Jorge Amado, \\ Salvador, Bahia
}

\section{Endereço para correspondência: Gabriel Ribeiro \\ Rua Osmar Macedo, quadra 22, lote 4, casa 5, Praias do Flamengo \\ - 41630-275 - Salvador, Bahia, Brasil. Tel.: (71) 9105-3242. \\ E-mail: fta_gabrielribeiro@yahoo. com.br}

Submetido em: 13/08/2008 Versão final recebida em: 04/05/2009 Aceito em: 05/05/2009

\begin{abstract}
RESUMO
A escápula possui funções essenciais no ombro do atleta de arremesso. Qualquer desequilíbrio presente entre as estruturas responsáveis pela sua estabilidade originará uma condição denominada discinesia escapular, a qual é comumente acompanhada de dor no ombro. Este estudo tem o objetivo de verificar se há associação entre a discinesia escapular e a dor no ombro de praticantes de natação. Foi realizado um estudo analítico observacional de corte transversal, incluindo 36 praticantes de natação do sexo masculino, com idade de 18 a 36 anos. Como métodos diagnósticos sugestivos de discinesia escapular foram utilizados o Slide Lateral Scapular Test e a filmagem proposta por Kibler. A existência de proporções significativas entre as variáveis nominais foi comprovada pelo teste do qui-quadrado ou pelo teste exato de Fisher. Para identificar associações entre as variáveis contínuas e os grupos de estudo foi utilizado o teste $t$ de Student. Um $p<0,05$ foi considerado estatisticamente significante. O grau de concordância interexaminador (Kappa; $p<0,0001$ ) foi considerado substancial, correspondendo a $86,1 \%(0,7656)$ no ombro direito e $83,3 \%(0,6412)$ no esquerdo. Constatou-se que a grande maioria (80\%) dos indivíduos que apresentaram positividade no Slide Lateral Scapular Test relatou dor no ombro. Dentre os nadadores que apresentaram discinesia escapular durante a filmagem, em 70,8\% também foi constatada a presença dessa condição no teste estático. Este é um estudo original no que diz respeito à abordagem da discinesia escapular em nadadores e em relacioná-la com a presença de dor no ombro. Porém, a hipótese inicial de que haveria uma associação significante não foi correspondida.
\end{abstract}

Palavras-chave: cinesiologia, lesões no esporte, articulação glenoumeral.

\begin{abstract}
The scapula plays an essential role in the throwing motion performed by athletes. Scapular dyskinesia is a condition characterized by imbalance in the structures responsible for the joint stability, which is often accompanied by shoulder pain. The main objective of this study is to assess the relationship between scapular dyskinesia and shoulder pain in swimmers. A total of 36 male swimmers aged between 18 and 36 years were diagnosed for scapular dyskinesia utilizing two different methods: the Lateral Slide Scapular Test and the video recording method suggested by Kibler. Statistical analysis was performed using the Chi-square test or Fisher's exact test. Comparisons between groups were performed using the t-test. The degree of $p<0.05$ was considered statistically significant. Significance was set at $\alpha=0.05$. There was a high inter-rate reliability concerning the video analysis (Kappa; $\mathrm{p}<0.0001$ ), corresponding to $86.1 \%$ (0.7656) on the right shoulder and $83.3 \%$ (0.6412) on the left shoulder. The majority of the individuals that had positive diagnosis assessed by the Lateral Slide Scapular Test (80\%) reported pain on the shoulder. Furthermore, $70.8 \%$ of the subjects who had positive diagnosis by the video recording also had positive diagnosis in the static test. Although a significant association between scapular dyskinesia and shoulder pain was not found, this is an important study to approach these conditions in swimmers.
\end{abstract}

Keywords: kinesiology, sports injuries, glenohumeral joint.

\section{INTRODUÇÃO}

A escápula possui funções essenciais no ombro do atleta de arremesso ${ }^{(1,2)}$. Sua estabilidade é conferida pelos músculos escapulares que a fixam ao tórax, posicionando adequadamente a cavidade glenoide em relação ao úmero e proporcionando uma base estável para o manguito rotador. A mobilidade da articulação glenoumeral deve estar em sintonia com a mobilidade escapulotorácica, obedecendo a uma relação de proporcionalidade durante a elevação do ombro, nos movimentos de abdução e flexão. Dessa forma, será possível uma adequada amplitude de movimento e o equilíbrio no padrão de ativação muscular. Qualquer desequilíbrio no ritmo escapulotorácico vai originar uma condição denominada discinesia escapular. Esta consiste na alteração do posicionamento e mobilidade normal da escápula em relação à caixa torácica ${ }^{(1,2)}$.

A disfunção escapular pode ser secundária a alterações posturais, patologias glenoumerais, como lesões labrais, impacto, tendinite do manguito rotador, ou como uma resposta de inibição muscular a um estímulo doloroso ${ }^{(1,2)}$. Discinesia escapular é um termo genérico que não designa exatamente o local onde ocorre a disfunção, portanto, Kibler et al. ${ }^{(3)}$ propuseram um sistema de avaliação de discinesia escapular que diferencia quatro padrões, sem referenciar a ordem de gravidade. No padrão tipo I, apenas o ângulo inferior da escápula encontra-se proeminente e, durante o movimento, o acrômio inclina-se anteriormente e o ângulo inferior inclina-se dorsalmente. A proeminência da 
borda medial da escápula no repouso e a inclinação dorsal da borda medial durante o movimento são características do tipo II. No tipo III, a borda superior da escápula permanece elevada no repouso e a escápula pode estar deslocada anteriormente; durante o movimento não é observada a inclinação dorsal da borda medial da escápula. 0 tipo IV é uma posição simétrica, na qual não se observam excessiva mobilidade e proeminência escapular ${ }^{(3,4)}$.

A alteração na mobilidade da cintura escapular tem sido relacionada com queixas de dor no ombro(1). O relato de dor é frequente em indivíduos que utilizam o membro superior em atividades repetitivas que impõem sobrecarga no ombro e que o submetem a posições elevadas, acima de 90 graus de abdução ou flexão. A alteração no ritmo escapuloumeral, consequente à fadiga muscular, vem sendo proposta como a causa mais provável da dor no ombro(5,6). Ejnisman ${ }^{(7)}$, em um estudo com 119 atletas com queixas relacionadas ao ombro, constatou que $72,2 \%$ deles apresentavam dor nessa região.

Apesar da sua importância, a cintura escapular não recebe a devida atenção durante a avaliação do complexo do ombro ${ }^{(1,8)}$. A presença associada da discinesia escapulotorácica e a referência de dor no ombro sugerem que existe uma relação de causalidade entre estas ${ }^{(9)}$. Dessa forma, pode-se pensar que o atleta de natação possui os fatores predisponentes de dor no ombro supracitados e a presença da dor pode interferir no seu desempenho máximo. Portanto, este estudo tem o objetivo de verificar a associação entre sintomatologia dolorosa e disfunção escapular em praticantes de natação, alertando para a importância da manutenção do equilíbrio muscular na região escapular. Além de constatar se praticantes de natação com discinesia escapular apresentam dor no ombro, o presente estudo teve como objetivos específicos verificar se o método de avaliação proposto por Kibler et al. através da filmagem possui confiabilidade entre os avaliadores e categorizar os achados de disfunção escapular de acordo com a classificação proposta por Kibler et al. ${ }^{(3,4)}$. A hipótese que norteia o estudo é de que a discinesia escapular é um achado frequente nos nadadores, assim como a queixa de dor no ombro, o que demonstra uma possível associação entre essas manifestações.

\section{MÉTODOS}

\section{Sujeitos}

Tratou-se de um estudo descritivo, no qual foi utilizada uma amostra não probabilística composta por praticantes de natação, do sexo masculino, com idade de 18 a 36 anos. Os critérios de exclusão foram a presença de cirurgia prévia e/ou fratura na região adjacente, história de capsulite adesiva, tempo de prática esportiva menor que um ano. Inicialmente foram entrevistados 37 praticantes de natação, porém, um participante teve que ser excluído por apresentar apenas um mês de prática.

Os dados utilizados foram de origem primária e os instrumentos de coleta foram a filmagem proposta por Kibler et al. ${ }^{(3)}$, o Slide Lateral Scapular Test ${ }^{(1)}$ e um formulário elaborado pelos autores, com questões relacionadas à idade, dominância, ocupação, uso repetitivo dos membros superiores nas atividades esportivas praticadas e laborais, frequência de treino, tempo de prática esportiva, presença de dor no ombro e localização da mesma.

\section{PROCEDIMENTOS}

Os dados foram coletados por um pesquisador em agosto de 2006, através da aplicação do formulário; da execução do Slide Lateral Scapular Test ${ }^{(1)}$, que consiste na mensuração da distância entre o ângulo inferior da escápula até o processo espinhoso correspondente, com o ombro a $0^{\circ}, 45^{\circ}$ e $90^{\circ}$ de abdução com o indivíduo em ortostatismo. De acordo com Kibler ${ }^{(20)}$, se essa medida fosse maior que $15 \mathrm{~mm}$ era sugestiva de discinesia escapular. Além desses procedimentos foi realizada uma filmagem, em condições pré-treino, no próprio clube esportivo, na qual o participante se encontrava em ortostatismo, de costas para a câmera, realizando o movimento ativo livre de abdução dos ombros no plano da escápula até aproximadamente $150^{\circ}$, por cinco vezes, de maneira rítmica e lenta. Os sujeitos foram instruídos a realizar o movimento em cinco segundos, cronometrados e contados em voz alta pelo pesquisador. A câmera da marca Olympus FE-115 manteve-se posicionada a um metro de distância do participante, suspensa sobre um tripé. Antes da gravação, os participantes eram treinados para a realização adequada do movimento desejado, realizando três repetições no ritmo supracitado. Os pontos correspondentes ao ângulo superomedial e inferomedial da escápula, foram demarcados com a ajuda de um lápis dermatográfico. Após a coleta dos dados, outros dois pesquisadores, que não tiveram acesso às informações obtidas nos testes e formulários, analisaram as filmagens da posição de repouso e do movimento, observando os seguintes pontos de referência escapulares: ângulo inferomedial, a borda medial, o ângulo superomedial e a borda superior. Posteriormente à observação, os pesquisadores categorizaram os achados baseados na classificação proposta por Kibler et al. ${ }^{(3)}$. A análise foi realizada separadamente e nos casos de discordância entre os autores realizou-se uma discussão com a finalidade de entrar em um consenso. Foi realizado um estudo- piloto com cinco praticantes de natação no mês de junho.

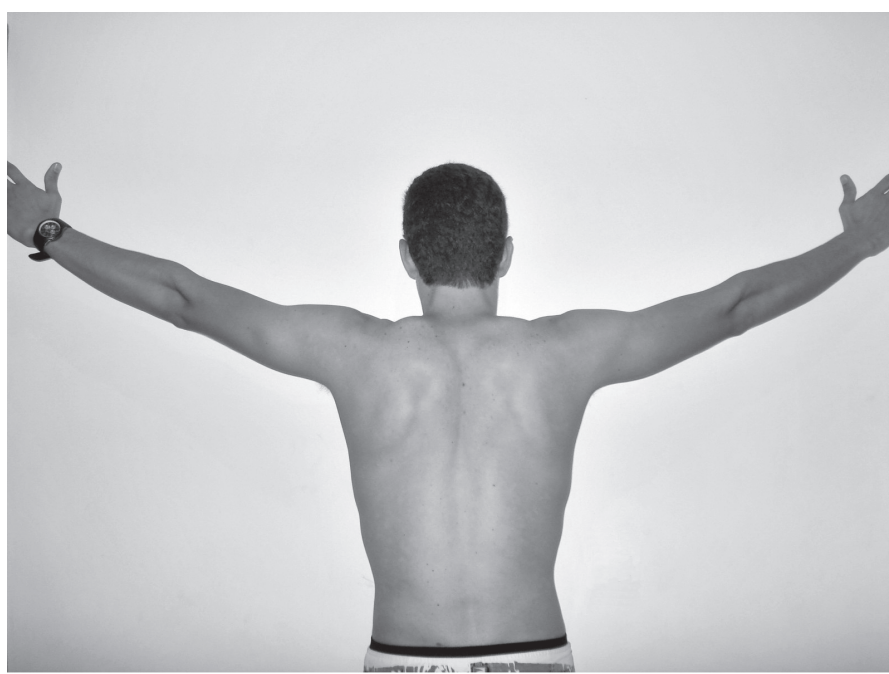

Figura 1. Fotografia ilustrando o movimento solicitado durante a realização do teste

\section{ANÁLISE ESTATÍSTICA}

O banco de dados foi estruturado no software Excel 2000 e analisado no software R 2.3.1, onde foi realizada a validação e correção dos dados digitados com o objetivo de eliminar possíveis erros ou inconsistência neles. Foi realizada uma análise descritiva (frequência absoluta/relativa, média aritmética e desvio padrão) com o objetivo de verificar as características específicas e gerais da amostra estudada. Para comprovar a existência de associações significativas entre as variáveis nominais (dor dominância, ocupação, positividade no teste estático, tipo de discinesia) foi usado o teste do qui-quadrado. Nas associações realizadas em que este não pôde ser validado, foi utilizado o teste exato de Fisher. Para identificar diferenças significativas entre as médias de idade e tempo de prática esportiva em relação à presença de dor e o resultado do teste, foi utilizado o teste $t$ de Student. O grau de concordância interexaminador, ou seja, o nível de confiabilidade do teste quando analisado por diferentes examinadores, foi avaliado pelo índice Kappa. Foram consideradas como estatisticamente significantes associações com $p<0,05$ 


\section{ASPECTOS ÉTICOS}

Este projeto de pesquisa foi aprovado pelo Comitê de Ética em Pesquisas da Escola Bahiana de Medicina e Saúde Pública sob protocolo de no 133/2008. Foi elaborado um termo de consentimento livre e esclarecido, no qual foram expostos os objetivos do trabalho para todos os participantes, sendo garantidos o anonimato e a confidencialidade dos dados, de acordo com os aspectos éticos concebidos pela Resolução 196/96 do Conselho Nacional de Ética em Pesquisas envolvendo seres humanos.

\section{RESULTADOS}

Foram analisados 36 praticantes de natação quanto à presença da discinesia escapular e/ou dor no ombro.

De acordo com o índice Kappa, o grau de concordância interexaminador na análise das filmagens foi substancial, $86,1 \%(p=0,7656)$ no ombro direito e 83,3\% ( $p=0,6412)$ no ombro esquerdo.

A média da idade do grupo foi de $25,1 \pm 4,7$ anos, variando de 18 a 36 anos. Além da natação, as outras atividades esportivas praticadas foram classificadas em atividades que não impõem sobrecarga excessiva nos membros superiores (MMSS) como futebol, ciclismo e corrida (72,2\%) e atividades que sobrecarregam os MMSS como surfe, musculação, tênis, voleibol e basquetebol (27,8\%). Ao serem questionados se a ocupação exercida no momento exigia o uso repetitivo dos MMSS, 15 nadadores $(41,7 \%)$ relataram que não. Com relação à dominância, apenas dois participantes $(5,6 \%)$ eram sinistros. $O$ tempo de prática de natação foi em média de 10,3 $\pm 6,1$ anos. A maior parte do grupo $(47,2 \%)$ treinava com frequência de seis vezes por semana, seguido de quatro vezes por semana (22,2\%), cinco vezes semanais $(16,7 \%)$ e, por último, sete vezes semanais $(13,9 \%)$.

A maioria dos indivíduos $(86,1 \%)$ apresentou história de dor no ombro. Assim como a dominância apresentou predileção pelo hemídio direito, os nadadores também apresentaram mais dor no ombro direito (58,1\%), seguido de $25,8 \%$ referindo dor no ombro esquerdo e 16,1\% em ambos os ombros. A localização exata da dor situou-se com maior frequência no processo coracoide $(45,2 \%)$, seguida de 19,4\% na região lateral (subacromial), 16,1\% na região posterior e 16,1\% na região anterior de forma geral, e, por último, ficaram a região superior (articulação acromioclavicular) e o tendão bicipital (9,7\%). Quando foram questionados sobre a presença de dor durante o treino, 58\% dos 31 nadadores que já apresentaram história de dor relataram que essa era uma constante durante a prática esportiva, e 41,9\% relataram sua ausência (tabela 1).

Tabela 1. Frequência absoluta e relativa da história, localização e referência da dor durante o treino de 36 praticantes de natação.

\begin{tabular}{l|c|c}
\hline \multicolumn{1}{c|}{ Dor } & N & $\%$ \\
\hline História de dor & 31 & \\
Sim & 5 & 86,1 \\
Não & & 13,9 \\
Localização (ombro) & 18 & \\
Direito & 8 & 58,1 \\
Esquerdo & 5 & 25,8 \\
Ambos & & 16,1 \\
Localização específica da dor & 5 & \\
Anterior (não localizada) & 14 & 16,1 \\
Processo coracoide & 3 & 45,2 \\
Tendão bicipital & 6 & 9,7 \\
Lateral (subacromial) & 3 & 19,4 \\
Superior (art. acromioclavicular) & 5 & 9,7 \\
Posterossuperior & & 16,1 \\
Dor durante o treino & 18 & 58 \\
Sim & 13 & 41,9 \\
Não & & \\
\hline
\end{tabular}

Com relação à avaliação da discinesia escapular, na tabela 2 estão expostos os achados de acordo com o teste dinâmico, que é a filmagem proposta por Kibler et al. ${ }^{(3)}$ e os achados com relação ao teste estático, que é o Slide Lateral Scapular Test ${ }^{(1)}$. Vinte e cinco nadadores $(69,4 \%)$ apresentaram assimetria acima de $15 \mathrm{~mm}$ no Slide Lateral Scapular Test ${ }^{(1)}$. A filmagem constatou que a maioria (58,3\%) dos nadadores apresentou algum tipo de assimetria em algum dos dois ombros. A outra parte dos indivíduos $(41,7 \%)$ apresentava simetria entre o posicionamento e a mobilidade escapular, configurando o tipo IV do sistema de avaliação dinâmica preconizado por Kibler et al.(3). Menos da metade dos indivíduos $(47,2 \%)$ apresentavam algum tipo de discinesia escapular no ombro direito enquanto que 33,3\% mostravam essa mesma característica no ombro esquerdo. No ombro direito, em ordem decrescente, aparece o tipo I com 22,2\% dos praticantes de natação, em seguida vem o tipo II englobando 19,4\% da amostra e, por último, o tipo III formando 5,6\%. No ombro esquerdo a ordem de aparecimento seguiu o mesmo padrão (tabela 2).

Tabela 2. Presença da discinesia escapular segundo os testes estático e dinâmico.

\begin{tabular}{l|c|c}
\multicolumn{1}{c|}{ Presença de discinesia escapular } & N & $\%$ \\
\hline Slide Lateral Scapular Test & 25 & \\
Positivo & 11 & 69,4 \\
Negativo & & \\
Sistema de avaliação dinâmica proposto por & & \\
Kibler et al. & & \\
Ombro direito & 8 & 22,2 \\
Tipo I & 7 & 19,4 \\
Tipo II & 2 & 5.6 \\
Tipo III & 19 & 52,8 \\
Tipo IV & & \\
Ombro esquerdo & 8 & 22,2 \\
Tipo I & 3 & 8,3 \\
Tipo II & 1 & 2,78 \\
Tipo III & 24 & 66,7 \\
Tipo IV & & \\
Prevalência de discinesia escapular inespecífica & & \\
avaliada através da filmagem & & \\
Ombro direito & 19 & 52,8 \\
Não & 17 & 47,2 \\
Sim & & \\
Ombro esquerdo & 24 & 66,7 \\
Não & 12 & 33,3 \\
Sim & & \\
Presença de algum tipo de discinesia em algum & & \\
ombro & & 33,3 \\
Não & & 66,7 \\
Sim & & \\
\hline & & \\
\hline & & \\
\hline & & \\
\hline
\end{tabular}

Ao estabelecer uma relação entre os dados obtidos, constatou-se que a grande maioria (80\%) dos indivíduos com positividade no Slide Lateral Scapular Test ${ }^{(1)}$ apresentou dor no ombro. Noventa e três por cento dos participantes que relataram utilizar os membros superiores exaustivamente em sua ocupação apresentaram dor no ombro. Os indivíduos que não apresentaram assimetria escapular, de acordo com o teste estático, obtiveram média de 10,7 \pm 5,7 anos de prática esportiva, enquanto que aqueles com essa condição possuíam média de 10,1 $\pm 6,4$ anos. Ao relacionar o tempo de prática esportiva com a referência de dor, encontrou-se que aqueles que já sentiram dor no ombro apresentavam média de 10,6 $\pm 6,1$ anos de prática e os nadadores que nunca sentiram dor no ombro formaram média inferior de $7,8 \pm 6,5$ anos de natação. Dentre os nadadores que apresentaram discinesia escapular durante a filmagem, em 70,8\% também foi cons- 
tatada a presença dessa condição no teste estático. Com relação ao ombro no qual a dor está presente, em indivíduos destros, $60 \%$ deles relataram dor no ombro direito, 23,3\% referiram dor no ombro esquerdo e 16,7\% admitiram história de dor em ambos os ombros. O único indivíduo sinistro que referiu dor relata que esta ocorreu no ombro esquerdo. Esses dados estão expostos nos gráficos, porém, devido ao pequeno número amostral, eles não obtiveram significância estatística (gráficos 1, 2 e 3).

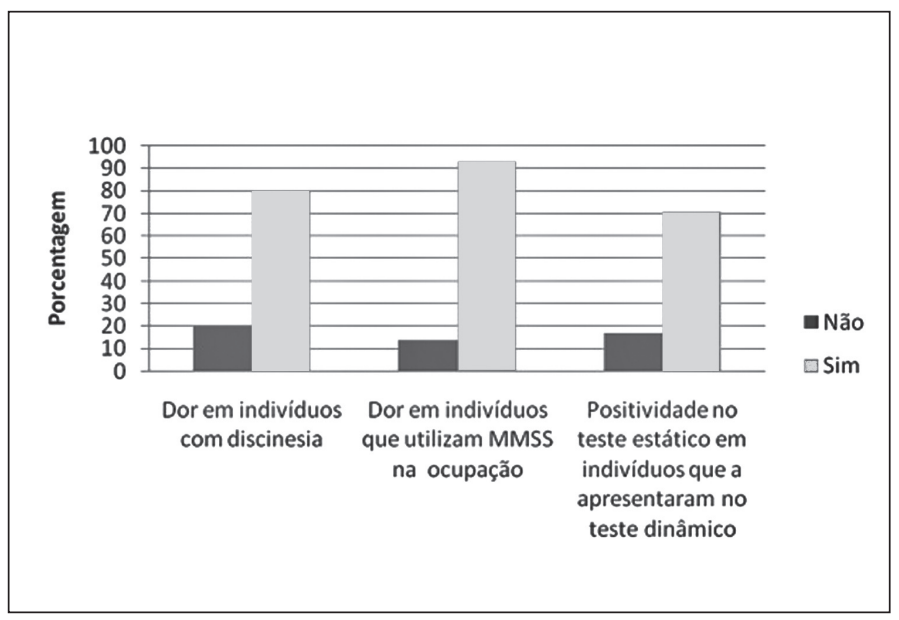

Gráfico 1. Associações entre os achados.

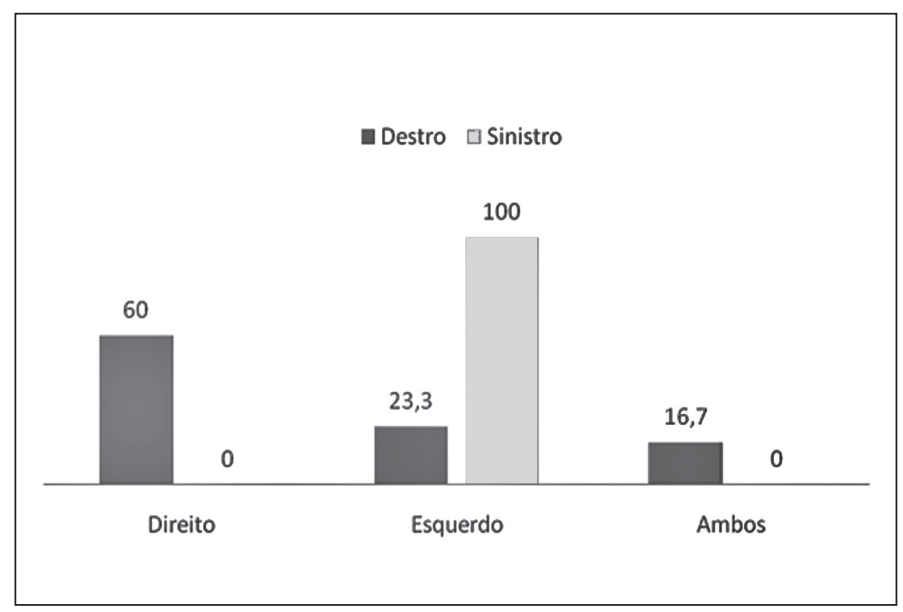

Gráfico 2. Localização da dor.

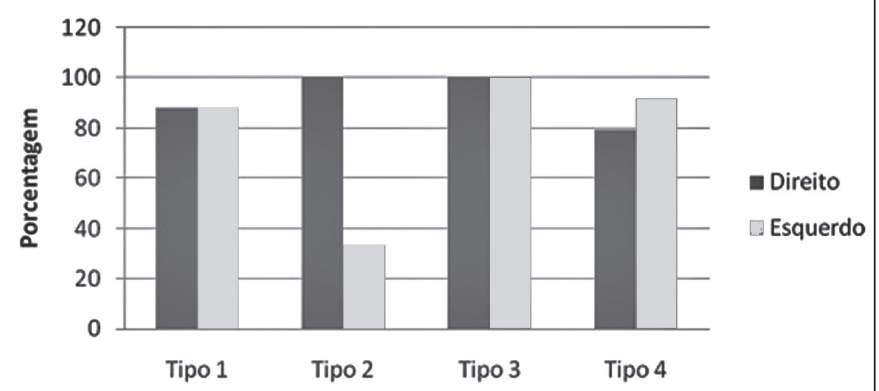

Gráfico 3. Índice de dor no ombro de acordo com os diferentes tipos.

\section{DISCUSSÃO}

No presente estudo não foi verificada relação estatisticamente significante entre a dor no ombro e a discinesia escapular. Foi constatada assimetria interescapular em 69,4\% dos participantes segundo o Slide Lateral Scapular Test, o que revela um alto índice. A literatura relata que alterações na posição e mobilidade escapular ocorrem em 68\% a $100 \%$ de indivíduos com lesões no ombro ${ }^{(1)}$. Entre os componentes da amostra com essa disfunção, 80\% apresentaram presença de dor no ombro. Kibler et al.(2) sugeriram um aumento da assimetria no ombro sintomático; entretanto, Odom et al. ${ }^{(10)}$ encontraram valores menores em ombros sintomáticos do que em ombros assintomáticos.

A avaliação da região periescapular é de difícil acesso devido à excessiva massa muscular que impede a visualização fidedigna das estruturas esqueléticas subjacentes. Além desse empecilho, a escápula não possui braços de alavanca para possibilitar uma avaliação quantitativa ${ }^{(11)}$, como a goniométrica, empregada nas articulações do esqueleto apendicular. Diante dessa situação, foi proposto por Kibler et al. um teste estático simples, de fácil execução, para a mensuração da posição escapular em três posturas diferentes ${ }^{(1,11)}$. McKenna et $a^{\left({ }^{(11)}\right.}$, em uma pesquisa com 15 atletas de natação, comprovaram que essa medida proposta por Kibler et al. possui boa confiabilidade interexaminador, porém, outro estudo, ao comparar indivíduos com ou sem alterações no ombro, demonstrou que essa forma de mensuração da assimetria escapular não é confiável ${ }^{(12)}$.

Os trapézios juntamente com o serrátil anterior formam um sistema de forças acopladas para prover a estabilidade dinâmica da escápula. A produção de força e o correto tempo de ativação muscular são fatores essenciais no funcionamento ótimo dos músculos estabilizadores da escápula ${ }^{(9)}$. Um estudo sugeriu que o serrátil anterior é o responsável pela mobilidade da escápula, enquanto os outros músculos trabalham para mantê-la estabilizada ${ }^{(13)}$ e essa estabilização escapular permanece durante a elevação do braço ao realizar a protração e a rotação para cima. Uma disfunção primária nesse músculo pode resultar em dor e discinesia escapulotorácica ${ }^{(14,15)}$ Ruwe et al. (12), ao avaliar competidores de natação com dor no ombro, demonstraram diminuição na atividade do trapézio superior durante a prática esportiva. Outro estudo verificou que o tempo de latência dos trapézios médio e inferior era maior em pacientes com sintomas de impacto do que em indivíduos saudáveis, levando a dominância do trapézio superior Esse desequilíbrio na musculatura escapulotorácica vai se configurar numa incoordenação da rotação escapular sobre a caixa torácica ${ }^{(9)}$.

Uma pesquisa comprova que existe um incremento no controle neuromuscular do ombro dominante em relação ao não dominante em atletas que utilizam o ombro em posições elevadas. Porém, na presença de uma lesão, essa rapidez no tempo de reação não é observada ${ }^{(9)}$. No presente estudo pôde-se observar que no único participante sinistro que apresentou dor no ombro, esta se localizou no ombro dominante, e dentre os participantes destros, 76,7\% tinham dor no ombro direito. Essa frequência elevada de dor no ombro dominante sugere que o uso excessivo deste predispõe a fadiga precoce, alterando o padrão de ativação muscular, culminando em uma disfunção escapulotorácica associada à dor.

A dor musculoesquelética geralmente é originária do encurtamento prolongado de grupos musculares que alteram o padrão normal de ativação muscular, conforme foi descrito em um estudo sobre a musculatura tônica e fásica ${ }^{(17)}$. Cools et al. ${ }^{(9)}$ observaram a predominância de déficits bilaterais em indivíduos que apresentavam apenas um ombro lesado. A partir desses achados, questiona-se sobre qual é o fenômeno primário. Ainda não está estabelecido se a disfunção escapulotorácica, aumentando o risco de impacto, promove o aparecimento da dor, ou se condições dolorosas propiciam a inibição dos músculos escapulotorácicos. Blanch defende que alterações na força, flexibilidade, padrão de ativação muscular e propriocepção são mais frequentes como causadores da dor do que consequência desta ${ }^{(16)}$. 
A prevalência de dor no ombro em nadadores que utilizavam os membros superiores exaustivamente em sua ocupação foi alta (93,3\%) no presente estudo. Dados da literatura relatam que essa é uma condição frequente em indivíduos que submetem seus braços ao uso repetitivo, posições acima de $90^{\circ}$ e cargas elevadas em atividades ocupacionais ou recreacionais. O mecanismo sugerido para explicação de tal fenômeno é a alteração da cinemática escapulotorácica consequente à fadiga muscular(5).

Pôde-se observar que os testes estático e dinâmico possuem uma concordância razoável quanto à classificação de presença ou não da discinesia escapular. A maioria (70,8\%) dos participantes com positividade no Slide Lateral Scapular Test também apresentou algum tipo de discinesia escapular na filmagem proposta por Kibler et al. ${ }^{(3)}$. Porém, não foi encontrado na literatura pesquisada nenhum relato sobre a relação entre essas duas formas de avaliação utilizada pelos autores.

Como foi descrito anteriormente nos resultados, o tipo IV do sistema de avaliação proposto por Kibler et al. ${ }^{(3)}$ consistiu na manifestação mais comum nos participantes desta pesquisa. Os dados científicos relatam que os tipos I e || são comumente associados a patologias labrais, enquanto que o tipo III é mais frequente em condições como impacto e lesões no manguito rotador ${ }^{(4)}$.

Recentemente foi descrita uma síndrome secundária ao uso excessivo da musculatura escapular, resultando em fadiga, e caracterizada por alteração no posicionamento escapular, proeminência da borda medial inferior, dor e mau posicionamento do processo coracoide, e discinesia do movimento escapular. Esta foi denominada de SICK e constitui uma importante causa de dor no ombro de atletas de arremesso que apresentam a "síndrome do braço morto". A síndrome da escápula SICK ocorre no ombro dominante e o indivíduo apresenta o ombro afetado mais inferior que o contralateral. Uma pesquisa realizada com atletas de beisebol assintomáticos comprovou que os saudáveis não apresentam os achados da síndrome SICK, e que a presença desta predispõe o atleta de arremesso a condições patológicas ${ }^{(4)}$. Porém, os dados aqui apresentados foram discordantes, já que todos os indivíduos que apresentaram negatividade do Slide Lateral Scapular Test referiram história de dor no ombro, enquanto que 80\% dos indivíduos com discinesia escapular segundo o mesmo teste apresentaram dor no ombro em algum momento da sua vida. Um dos motivos para essa controvérsia é o tamanho amostral reduzido. Outra justificativa seria que, por se tratar de praticantes de natação com tamanha frequência e prolongado tempo de prática esportiva, a probabilidade de apresentarem sintomatologia dolorosa é alta, secundária ao impacto subacromial, lesões labrais, entre outras causas, sem que necessariamente seja acompanhada de discinesia escapular.

\section{REFERÊNCIAS BIBLIOGRÁFICAS}

1. Kibler WB, McMullen J. Scapular dyskinesis and its relation to shoulder pain. J Am Acad Orthop Surg. 2003;11:142-51

2. Kibler WB. The role of the scapula in athletic shoulder function. Am J Sports Med. 1998;26:325-37.

3. Kibler WB, Uhl TL, Maddux JWQ, Brooks PV, Zeller B, McMullen J. Qualitative clinical evaluation of scapular dysfunction: a reliability study. J Shoulder Elbow Surg. 2002;11:550-6.

4. Burkhart SS, Morgan CD, Kibler WB. The disabled throwing shoulder: spectrum of pathology. Part III:The SICK Scapula, Scapular Dyskinesis, the Kinetic Chain, and Rehabilitation. Arthroscopy. 2003;19:641-61.

5. Ebaugh DD, McClure PW, Karduna AR. Effects of shoulder muscle fatigue caused by repetitive overhead activities on scapulothoracic and glenohumeral kinematics. J Electromyogr Kinesiol. 2006;16:224-35.

6. Ruotolo C. Shoulder pain and the overhand athlete. Am J Orthop. 2003;32:248-58.

7. Ejnisman B. Lesões musculo-esqueleticas no ombro do atleta: mecanismo de lesão, diagnóstico e retorno e prática esportiva. Rev Bras Ortop. 2001;36:389-93.

8. Meister K. Injuries to the shoulder in the throwing athlette Part one: biomechanics/ pathophysiology/ classification of injury. Am J Sports Med. 2000;28:265-75

9. Cools AM, Witvrow EE, Declerca GA, Danneels LA, Cambier DC. Scapular Muscle Recruitment Patterns: Trapezius Muscle Latency with and without Impingement Symptoms. Am J Sports Med. 2003;31:542-9.

10. Odom CJ, Taylor AB, Hurd CE, Denegar CR. Measurement of scapular asymmetry and assesment of shoulder dysfunction using the Lateral Scapular Slide Test: A rebiability and validity study. Phys Ther. 2001;81:799-809.
Os portadores da síndrome da escápula SICK apresentam mais comumente dor na região anterior, mais especificamente no processo coracoide. Nesta pesquisa, a maioria dos participantes $(45,2 \%)$ também relatou dor à palpação no processo coracoide. Na literatura, a frequência da localização da dor no ombro em ordem decrescente é: posterossuperior com ou sem irradiação, dor subacromial, dor na articulação acromioclavicular e, por último, sintomas radiculares. No presente trabalho, o local mais acometido por sintomas dolorosos após o processo coracoide foi a região subacromial (19,4\%), depois com os mesmos valores veio a região anterior de forma inespecífica e a posterossuperior (16,1\%), seguidas da articulação acromioclavicular e cabeça longa do tendão bicipital $(9,7 \%)^{(4)}$.

Myers et al., em um trabalho com com 21 atletas de arremesso no grupo teste e 21 indivíduos não atletas no grupo controle, constataram que os grupos possuíam a posição e orientação escapular diferentes. Foi observada excessiva mobilidade de rotação interna, elevação e retração escapular durante a elevação umeral nos atletas de arremesso, o que sugere que os mesmos tendem a desenvolver adaptações crônicas para melhorar o desempenho durante a prática esportiva ${ }^{(19)}$.

O atleta de natação, ao utilizar os MMSS como 90\% de sua força propulsiva, possui grande probabilidade de apresentar fadiga muscular ${ }^{(18)}$. Esta, por sua vez, vai constituir um importante fator de limitação para o máximo rendimento na prática esportiva, podendo originar uma desorganização no padrão de ativação muscular e, consequentemente, dor no ombro. Foi verificado no presente estudo que a alteração na musculatura escapulotorácica é frequente no nadador, assim como a dor no ombro. Faz-se necessário, portanto, que o ritmo escapuloumeral seja mantido em perfeito equilíbrio para que seja alcançado melhor desempenho.

Este é um estudo original no que diz respeito à abordagem da discinesia escapular em nadadores e em relacioná-la com a presença de dor no ombro. Porém, a hipótese inicial de que essas teriam uma associação significativa não foi correspondida. Um dos prováveis motivos da nulidade da hipótese é que o número amostral foi insuficiente ou que a variabilidade da amostra possa ter influenciado. A utilização da filmagem como meio de avaliação pode ser considerada como uma limitação da pesquisa, pois não permite ao avaliador uma visão nos três planos, mas este foi o método mais acessível encontrado pelos pesquisadores. São necessárias novas intervenções com amostras mais robustas para substanciar os dados até então existentes, além de investigações sobre possíveis relações entre os tipos de discinesia e diagnósticos específicos.

\section{CONCLUSÃO}

Nossos achados evidenciaram altos índices de discinesia escapular em praticantes de natação, demonstrados através da frequente presença de desequilíbrio entre as forças que mantêm o posicionamento da cintura escapular, mensurado através de testes estáticos e dinâmicos.

11. McKenna L, Cunningham J, Straker L. Inter-tester reliability of scapular position in junior elite swimmers. Physical Therapy in Sport. 2004;5:146-55.

12. Ruwe PA, Pink M. Jobe FW. The normal and the painful shoulders during the breaststroke. Electromyographic and cinematographic analysis of twelve muscles. Am J Sports Med. 1994;22:789-96.

13. Prentice WE, Voight ML. Técnicas em Reabilitação Musculoesquelética. Porto Alegre: Artmed, 2003. $727 \mathrm{p}$.

14. Warner JJ, Navarro RA. Serratus anterior dysfunction. Recognition and treatment. Clin Orthop Relat Res. 1998;(349):139-48

15. Fox JA, Cole BJ. Pectoralis Major Transfer for Scapular Winging; Operative Techniques in Orthopaedics. 2003;13:301-7.

16. Blanch P. Conservative management of shoulder pain in swimming. Phys Ther Sport. 2004;5:109-24.

17. Janda V. Muscle weakness and inhibition (pseudoparesis) in back pain syndromes, in Grieve GP, editor: Modern Manual Therapy of the vertebral Column. Edinburgh, Churchill Livingstone. 1986, pp. 197-201.

18. Pink MM, Tibone JE. Conservative management of shoulder injuries: The painful shoulder in the swimming athlete. Orthop Clin North Am. 2000;31:247-61

19. Myers JB, Laudner KG, Pasquale MR, Bradley JB, Lephart SM. Scapular position and orientation in thowing athletes. Am J Sports Med. 2005;33:263-71.

20. Kibler WB. Role of the scapula in the overhead throwing motion. Contemp Orthop. 1991;22:525-32. 